\title{
Relationship between volume flow and velocity in the cerebral circulation'
}

\author{
J. O. ROWAN, A. M. HARPER, J. D. MILLER ${ }^{2}$, G. M. TEDESCHI ${ }^{3}$, AND \\ W. B. JENNETT
}

From the Department of Neurosurgery and the Wellcome Surgical Research Institute, University of Glasgow, Regional Department of Clinical Physics and Bio-Engineering,

and

The Institute of Neurological Sciences, Glasgow

SUMMARY The relationship between the velocity of the cerebral circulation and the cerebral blood flow was explored at varying levels of $\mathrm{PaCO}_{2}$, systemic arterial pressure, intracranial pressure, and perfusion pressure, using radioisotope techniques in baboons. Only at low flow rates did velocity increase with flow, and then non-linearly; at high rates velocity increased progressively less. Changes in flow are reflected by changes in velocity in such restricted circumstances that mean circulation time is a very unreliable indication of cerebral blood flow.

The introduction of the inert gas clearance method of estimating regional cerebral blood flow (rCBF) using radioactive inert gases (Lassen and Ingvar, 1961) set off a spate of experimental and clinical investigations of the cerebral circulation. A quantitative measurement of the regional volume flow (rCBF) in $\mathrm{ml} . / 100 \mathrm{~g}$ $/ \mathrm{min}$ is obtained by measuring the rate of clearance from the brain of ${ }^{85} \mathrm{Kr}$ or ${ }^{133} \mathrm{Xe}$ but the method has been restricted in its use because of the need to puncture the carotid artery for injection of the isotope. The administration of the isotope by inhalation is possible but introduces considerable problems in interpretation (Veall and Mallett, 1966; Obrist, Thompson, King, and Wang, 1967). The measurement of the mode circulation time (MCT) through the brain of a non-diffusible isotope after intravenous injection has been proposed as a less traumatic method for investigating the cerebral circulation (Oldendorf and Kitano, 1964). Although this provides information only about the velocity of the circulation, claims have been made for its value in clinical practice: 'The assumption that cerebral blood flow is a reciprocal of mean circulation time

\footnotetext{
${ }^{2}$ This study was supported by the Medical Research Council.

'Present address: Department of Neurosurgery, Hospital of the University of Pennsylvania, U.S.A.

${ }^{3}$ NATO Scholar from the University of Naples.
}

will not lead to error at the clinical level' (Kak and Taylor, 1967b).

The purpose of the present study, carried out on baboons, was to determine the validity of this claim by exploring the relationship between rCBF and MCT under varying physiopathological conditions. Cerebral circulation was deliberately stressed by altering either the arterial level of carbon dioxide $\left(\mathrm{PaCO}_{2}\right)$, or the cerebral perfusion pressure (CPP). The latter is defined as systemic arterial pressure (SAP) minus intracranial pressure (ICP); it can therefore be manipulated by altering either the SAP or the ICP, or both.

\section{METHOD}

1. PREPARATION OF ANimal Baboons weighing approximately 10 to $12 \mathrm{~kg}$ were used. After tranquillizing with phencyclidine (10 mg intramuscularly) anaesthesia was induced with an intravenous injection of sodium thiopentone $(15 \mathrm{mg} / \mathrm{kg})$, repeat doses of $5 \mathrm{mg} / \mathrm{kg}$ being administered when necessary during the surgical procedure. The animals were intubated and controlled ventilation established using a Starling pump, the stroke volume of which could be adjusted to maintain a constant $\mathrm{PaCO}_{2}$. After the surgery, phencyclidine $(2 \mathrm{mg})$ and suxamethonium $(50 \mathrm{mg})$ were administered intramuscularly at half-hourly intervals. A mixture of nitrous oxide and oxygen (in the ratio $7: 3$ ) was delivered by the respiratory pump in open circuit. A femoral artery and vein were 733 
cannulated and catheters advanced up each to midabdominal level. After reflection of the scalp and temporal muscle from one side of the head, a frontal burr hole was made and a hollow bolt screwed into it for measurement of ICP. The carotid bifurcation was exposed on one side, and the external carotid artery was ligated. A fine catheter was introduced into the common carotid artery below the bifurcation, using a modified Seldinger technique. In those animals to be subjected to raised ICP a cannula was passed percutaneously into the cisterna magna and connected to a reservoir of mock CSF$^{1}$, maintained at body temperature by a water bath. The CSF reservoir could be pressurized using a sphygmomanometer bulb connected with an aneroid manometer. Finally the detectors were put in position, that for rCBF over the frontoparietal region and that for MCT over the inion.

2. CEREBRAL CiRCULATION MEASUREMENTS a. $r C B F:$ A bolus or slug injection of $0.5 \mathrm{mCi}$ of the diffusible inert gas ${ }^{133} \mathrm{Xe}$, dissolved in 0.5 to $0.75 \mathrm{ml}$. saline at $37^{\circ} \mathrm{C}$, was injected into the carotid artery. The rate of clearance of gamma activity is dependent on blood flow, and was measured using a collimated 1 in. sodium iodide crystal detector. The output pulses from this detector, after amplification and pulse height analysis, were fed via a digital tape recorder and ratemeter to a chart recorder, and a recycling scaler and printer. CBF was calculated by height-over-area technique over a period of 10 minutes (Zierler, 1965; Høedt-Rasmussen, 1967).

b. MCT: The non-diffusible indicator ${ }^{131} \mathrm{I}$-hippuran was rapidly injected into the inferior vena cava through the femoral vein. The passage of isotope through the brain was monitored by a similar detector system, using an amplifier, pulse height analyzer, tape recorder, and ratemeter, the output of which was filtered and electronically differentiated. The peaks of the resultant bipolar wave form indicate the maximum rate of entry of activity into the field of view of the detector, and the maximum rate of exit from this field; the time between the peaks is the mode transit time.

3. OTHER MEASUREMENTS a. Intracranial pressure (ICP) was recorded from the extradural space using a salinefilled system consisting of a hollow metal bolt screwed into a frontal burr hole connected to a pressure transducer. The output of the transducer was fed to one channel of a dual-channel chart recorder.

b. Systemic arterial pressure (SAP) was recorded from a catheter placed in the aorta through a femoral artery, and connected to a pressure transducer, the output of which was fed to the other channel of the chart recorder.

c. Arterial and sagittal sinus blood $\mathrm{pO}_{2}, \mathrm{pCO}_{2}$, and $\mathrm{pH}$ were measured with direct reading electrodes (Radiometer), making the necessary correction for body temperature (as recorded from a pharyngeal thermometer).

d. The end-expiratory carbon dioxide concentration was continually monitored using an infra-red analyzer (Capnograph-Godart 119).

${ }^{1}$ Formula (in m-equiv/l.) for mock CSF: Na 145.0, K 3.5, Cl 121.5, $\mathrm{H}_{2} \mathrm{PO}$, $2 \cdot 0, \mathrm{HCO}_{3} 25 \cdot 0$.
4. EXPERIMENTS Four different experiments were $\bar{Z}$ performed:

a. In seven animals the $\mathrm{PaCO}_{2}$ was raised by adding $\mathrm{CO}_{2}$ to the inspired gas mixture, or lowered by increasing $\mathscr{f}$ the stroke volume of the respiratory pump. When the $\overrightarrow{\widehat{\theta}}$ expired $\mathrm{CO}_{2}$ concentration had been steady for five $\circlearrowright$ minutes, as shown on the infra-red analyzer, arterial samples were taken and circulation studies carried out; $\stackrel{?}{\rightarrow}$ first the MCT was measured and then, a minute later, the injection of Xenon was made and the rCBF calculated over the next 10 minutes.

b. In six animals the perfusion pressure was reduced $\stackrel{\overline{\vec{D}}}{\stackrel{\bar{O}}{0}}$ by raising the ICP by infusion of mock CSF into the $\overline{0}$ cisterna magna. This was carried out stepwise, watching the continuous recording of ICP, to allow for distribution of pressure through the head and to enable compensatory mechanisms to operate; and also to avoid a catastrophic reaction of the medulla to sudden injection.

c. In five animals the perfusion pressure was reduced by inducing arterial hypotension. After 50 to $100 \mathrm{ml}$. blood had been removed from the femoral vein and heparinized to allow re-injection if necessary later in the experiment, Arfonad (trimetaphan camphorsulphonate) was injected and the arterial pressure adjusted by tilting the operating table in either direction. In early experi- $\dot{\omega}$ ments a continuous infusion of Arfonad was used but it $\omega$ proved difficult to maintain a stable pressure for long enough to complete the rCBF runs. We found it morg $\mathrm{\omega}_{\mathrm{W}}$ practical to give a single injection of 25 to $50 \mathrm{mg}$ which would produce an immediate fall in pressure with ver? slow recovery over one to two hours, during which we could carry out 10-minute runs at various levels.

d. In six animals the perfusion pressure was increase by infusing angiotensin intravenously.

\section{RESULTS}

This paper is concerned with the comparison of MCT and rCBF. In Figs. 1, 3, 4, and 5, the reciprocal of MCT is plotted on the $y$-axis and $\mathrm{rCBF}$ on the $\mathrm{x}$-axis so that increases in both parameters will be indicated in a positive direction, as a percentage change from control values $(100 \%)$; the control values are shown in the Table.

\section{TABLE}

CONTROL VALUES

$$
(=100 \%)
$$

\begin{tabular}{lcccc}
\hline & $\begin{array}{c}\text { Changing } \\
\text { PaCO }\end{array}$ & $\begin{array}{c}\text { Increased } \\
\text { ICP }\end{array}$ & $\begin{array}{c}\text { Decreased } \\
\text { SAP }\end{array}$ & $\begin{array}{c}\text { Increased } \\
\text { SAP }\end{array}$ \\
\hline Baboons (no.) & 7 & 6 & 5 & 6 \\
CBF (ml./100 g/min) & 48 & 48 & $75^{*}$ & 58 \\
MCT (sec) & $7 \cdot 1$ & $9 \cdot 1$ & $6 \cdot 9$ & $6 \cdot 5$ \\
PaCO (mm Hg) & 38 & 35 & 43 & 38 \\
Perfusion pressure & & 89 & 83 & 106 \\
(mm Hg) & - & & &
\end{tabular}

*This mean was heavily weighted towards a high value as a result of two unusually high control flow values. 


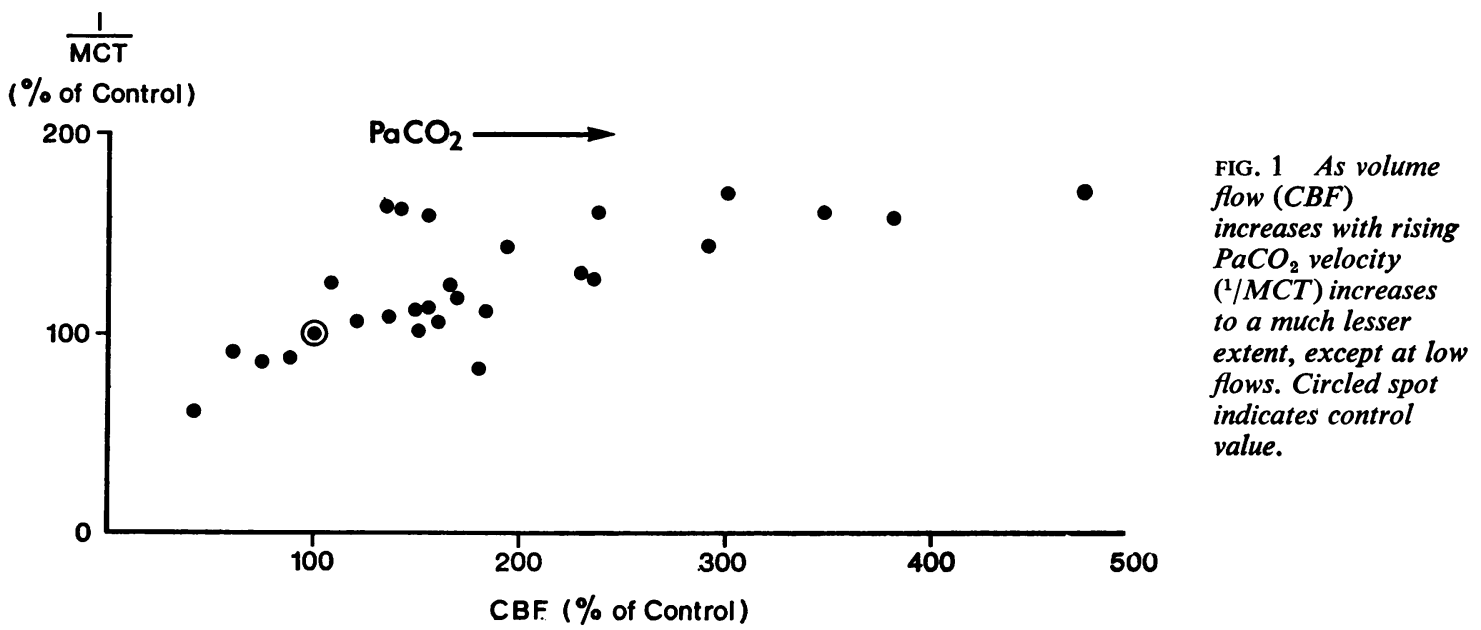

a. CHANGING $\mathrm{PaCO}_{2}$ (range $=19-150 \mathrm{~mm} \mathrm{Hg}$ over seven animals) As rCBF increased in stages from the hyperventilated state to the hypercapnic state no linear relationship was seen between the relative velocity (reciprocal of MCT) and rCBF except over a small range at low flow rates (Fig. 1). As flow increased the curve flattened so that at relatively high flow rates there was little further change in mode circulation time. However, under these conditions ICP continued to rise, suggesting further vasodilatation with consequent increase in brain blood volume - that is, at high flow rates changes in flow were associated with much greater changes in blood volume than in blood velocity (Fig. 2).

b. CHANGING PERFUSION PRESSURE (ICP range 2 to $133 \mathrm{~mm} \mathrm{Hg}$ : SAP range 203 to $21 \mathrm{~mm} \mathrm{Hg}$ ) Whether

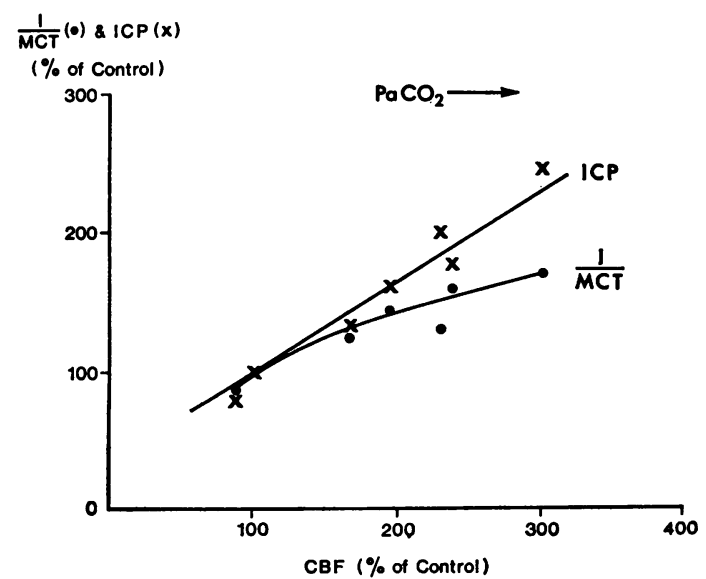

FIG. 2. As the increase in velocity levels off the increase in ICP continues, indicating continued vasodilatation. (Data from single baboon.) perfusion pressure was changed by varying ICP or SAP the graphs of the reciprocal of MCT against rCBF exhibit the same contour as that shown when these two parameters were compared under conditions of changing $\mathrm{PaCO}_{2}$ (Fig. 3).

Some of the high flow rates obtained in these series of experiments require further explanation. When the intracranial pressure was raised two different types of $\mathrm{CBF} /$ perfusion pressure relationships were observed. In some animals the blood flow remained more or less constant until the perfusion pressure fell below $35 \mathrm{~mm} \mathrm{Hg}$, while with others there was a marked increase in flow at a pressure in the region of $40 \mathrm{~mm} \mathrm{Hg}$, before the expected drop in flow (Fig. 4). This increase in flow was always accompanied by a Cushing response of rising blood pressure, which was never observed in animals showing no increase in flow. This phenomenon is being investigated and will be the subject of another paper.

During infusion of angiotensin it proved difficult to maintain a constant $\mathrm{PaCO}_{2}$ and some of the high flows obtained with this series of experiments resulted from hypercapnia. These observations will not be discussed further in this paper, which is concerned only with the relationship between MCT and $\mathrm{rCBF}$.

\section{DISCUSSION}

HAEMODYNAMICS In the situations described in the four series of experiments the diameters of the blood vessels are changing due to either a $\mathrm{CO}_{2}$ effect or to an autoregulatory process until the limit is reached.

We can write $\mathrm{F}=\frac{V}{\bar{t}}\left\{\begin{array}{l}\mathrm{F} \text {-volume flow per unit time } \\ \mathrm{V} \text {-brain blood volume } \\ \bar{t} \text {-mean transit time }\end{array}\right.$ 


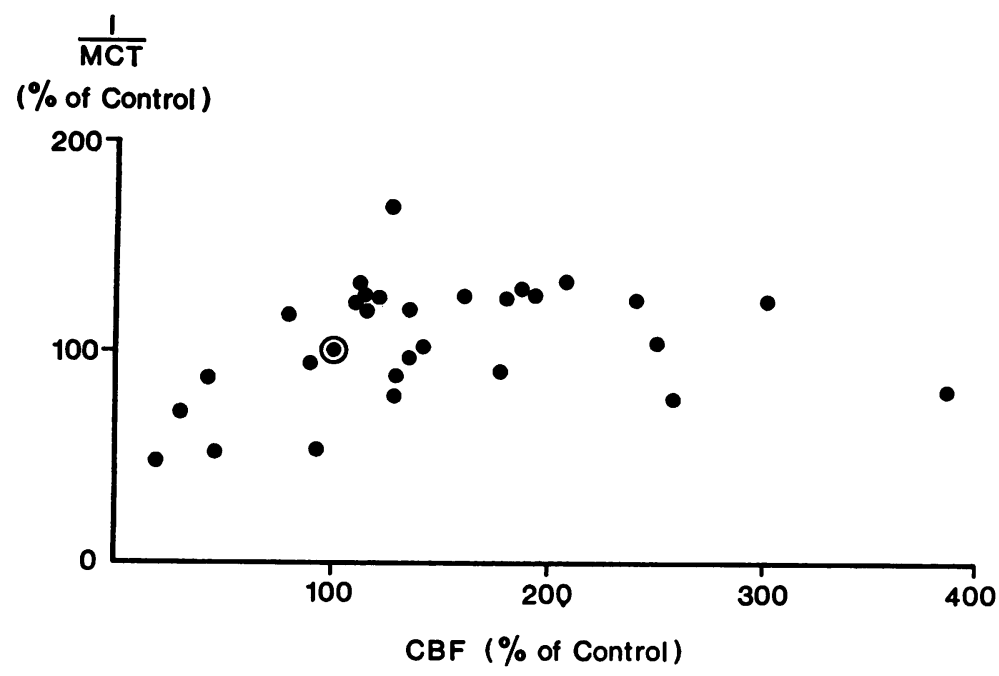

FIG. 3. Only at low flows does velocity $(1 / M C T)$ increase with increasing $C B F$, as perfusion pressure varies. Circled spot indicates control value.

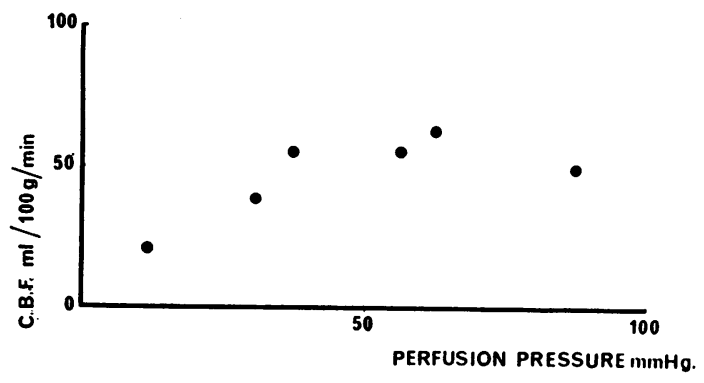

FIG. 4a. As perfusion pressure is reduced by increasing ICP, the CBF is maintained until PP is $<50 \mathrm{~mm} \mathrm{Hg}$ (baboon without Cushing response).

If we make no assumptions about the constancy of brain blood volume, mean transit time becomes an index only of velocity; in the same way mode transit time can be used as a velocity index. From Poiseuille's basic equation for laminar flow through rigid tubes it can be shown that the mean velocity is proportional to the square of the tube radius, while volume flow per unit time is proportional to the fourth power of the radius.

$$
\begin{aligned}
& u \quad \text {-velocity } \\
& p_{1}-p_{2} \text { - } \text { - pressure difference } \\
& r \quad \text { - tube radius } \\
& z \quad \text { - distance from tube axis } \\
& n \quad \text { - coefficient of viscosity } \\
& l \quad \text { - length of tube } \\
& F \quad \text { - volume flow per unit time } \\
& \qquad \frac{u=\left(p_{1}-p_{2}\right)\left(r^{2}-z^{2}\right)}{4 n l}
\end{aligned}
$$

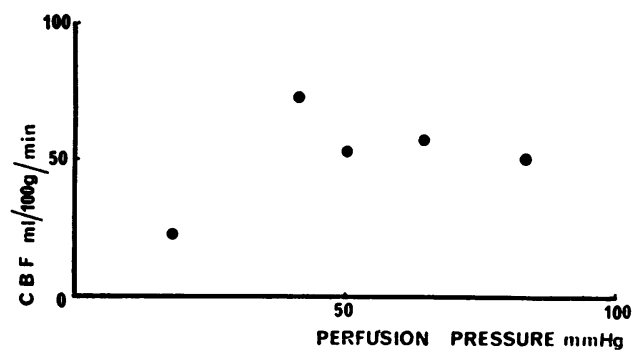

FIG. 4b. Before fall in $C B F$ at low PP an increase in $C B F$ (hyperaemia) is recorded (baboon with Cushing response).

$$
\begin{gathered}
\text { Mean velocity }=\bar{u}=\frac{1}{r_{0}} \int \frac{r\left(p_{1}-p_{2}\right)\left(r^{2}-z^{2}\right) \mathrm{d} z}{4 n l} \\
=\frac{\left(p_{1}-p_{2}\right) r^{2}}{6 n l} \\
\text { i.e. } \bar{u} \alpha r^{2} \text { or } \frac{\bar{u}_{1}}{\bar{u}_{2}}=\frac{r_{1}^{2}}{r_{2}^{2}} \\
F=\frac{\left(p_{1}-p_{2}\right) \pi r^{4}}{8 n l} \\
\text { i.e. } F a r^{4} \text { or } \frac{F_{1}}{F_{2}}=\frac{r_{1}^{4}}{r_{2}^{4}}=\left[\frac{r_{1}{ }^{2}}{{r_{2}}^{2}}\right]^{2}=\frac{\bar{u}_{1}^{2}}{\bar{u}_{2}^{2}}
\end{gathered}
$$

$\therefore \bar{u}^{2} \alpha F$ (under conditions of changing radius)

From simple theory, then, the most fundamental relationship that could exist between velocity and flow volume under situations of changing radius would be a parabolic one, thus resulting in a more marked change in flow than in velocity. 


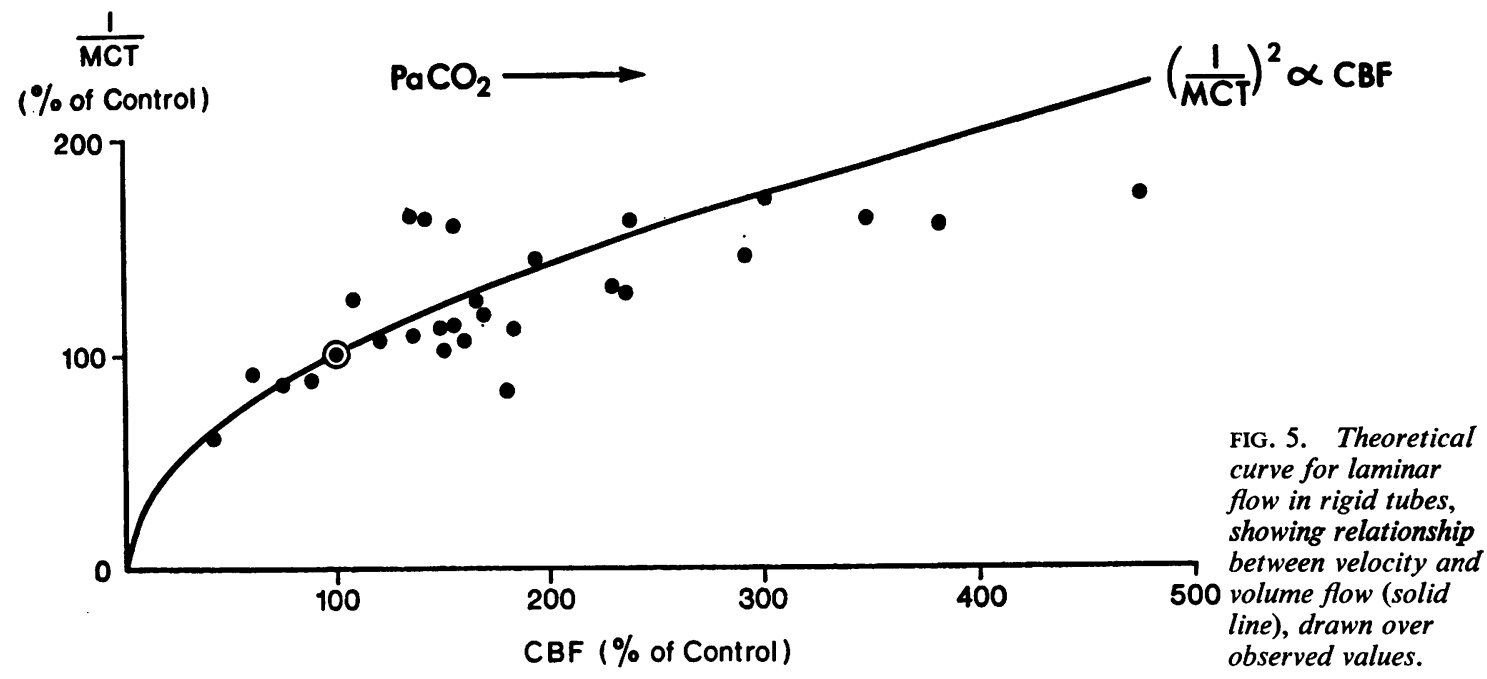

It proved interesting to see how the true situation deviated from this simple parabolic relationship. As an example, Fig. 5 shows the results for the hypercapnic series again but with the parabola (Relative Velocity $^{2}=\mathrm{CBF}$ drawn on the same scale. It will be seen that at normal and slow flow rates the experimental points lie close to the parabola, while at higher flow rates the velocity flattens out and moves away from the parabolic shape. The results of the other two series when plotted in this way show a similar pattern.

CLINICAL IMPLICATIONS Over a limited range of relatively low flows velocity does change with flow, but not linearly. The clinical conditions for which a correlation has been claimed between velocity and other factors commonly regarded as altering flow, have each concerned the restoration of reduced flow to normal: recovery from head injury (Taylor and Bell, 1966); recovery from subarachnoid haemorrhage associated with spasm (Kak and Taylor, 1967a); and the treatment of senile dementia with vasodilators (Ball and Taylor, 1967). In these particular situations serial circulation time measurements may find some application, but they can never indicate changes in flow in quantitative terms. Moreover, velocity measurements are not regional, although it is possible to discriminate between the left and right sides of the head (Jennett, 1968, 1970). Velocity measurements would therefore not be expected to show the abnormal increases in regional flow associated with brain damage of various kinds which rCBF measurements are now revealing in a wide variety of clinical situations (Brock et al., 1969).
Indeed, we have observed such hyperaemic responses in some of the present series of experiments; this hyperaemia was observed only by CBF measurements and was not reflected in change of velocity. The question remains whether circulation time could be useful as an initial screening procedure for various clinical intracranial conditions, perhaps indicating which patients should be investigated by angiography or by rCBF studies. Over 200 neurosurgical patients have now had MCT measurements in the Glasgow Institute, and many patients with gross intracranial pathology have shown no abnormality in the velocity in the circulation (Rowan, Cross, Tedeschi, and Jennett, 1970); this is in accord with the experimental findings reported here. The assumption that changes in flow will be reflected in changes in velocity is valid in such restricted circumstances that it would seem unwise to base clinical decisions on such measurements.

We wish to thank, for their assistance throughout this study, Mrs. S. Strachan, B.Sc., and her biochemistry staff ; also Mr. J. G. Littlejohn, Miss Isobel Sannholm, R.N., and the technical staff of the Wellcome Surgical Research Institute.

\section{REFERENCES}

Ball, J. A. C., and Taylor, A. R. (1967). Effect of cyclandelate on mental function and cerebral blood flow in elderly patients. Brit. med. J., 3, 525-528.

Brock, M., Fieschi, C., Ingvar, D. H., Lassen, N. A., and Schurmann, K. (1969). Cerebral Blood Flow. Springer: Berlin.

Høedt-Rasmussen, K. (1967). Regional Cerebral Blood Flow. Munksgaard: Copenhagen.

Jennett, W. B. (1968). Experimental studies on the cerebral 
circulation: clinical aspects. Proc. roy. Soc. Med., 61, 606612.

Jennett, W. B. (1970). Cerebral blood flow measurement in clinical practice. In Cerebral Circulation (International Anesthesiology Clinics, vol. 7). Little, Brown: Boston.

Kak, V. K., and Taylor, A. R. (1967a). Cerebral blood-flow in subarachnoid haemorrhage. Lancet, 1, 875-877.

Kak, V. K., and Taylor, A. R. (1967b). Blood-flow in subarachnoid haemorrhage. Lancet, 1, 1061.

Lassen, N. A. , and Ingvar, D. H. (1961). The blood-flow of the cerebral cortex determined by radioactive Krypton. Experientia (Basel), 17, 42-43.

Obrist, W. D., Thompson, H. K. Jr., King, C. H., and Wang, H. S. (1967). Determination of regional cerebral blood flow by inhalation of 133-xenon. Circulation Res., 20, 124-135.

Oldendorf, W. H., and Kitano, M. (1964). The free passage of
$\mathrm{I}^{131}$ antipyrine through brain as an indication of $\mathrm{A}-\mathrm{V}$ shunting. Neurology (Minneap.), 14, 1078-1083.

Rowan, J. O., Cross, J. N., Tedeschi, G. M., and Jennett, W. B. (1970). Limitations of circulation time in the diagnosis of intracranial disease. J. Neurol. Neurosurg. Psychiat., 33, $739-744$.

Taylor, A. R., and Bell, T. K. (1966). Slowing of cerebral circulation after concussional head injury. A controlled trial. Lancet, 2, 178-180.

Veall, N., and Mallett, B. L. (1966). Regional cerebral blood flow determination by ${ }^{133} \mathrm{Xe}$ inhalation and external recording: the effect of arterial recirculation. Clin. Sci., 30, 353-369.

Zierler, K. L. (1965) Equations for measuring blood flow by external monitoring of radioisotopes. Circulation Res., 16, 309-321. 